archives-ouvertes

\title{
Doping of poly(3-hexylthiophene) nanofibers: microscopic morphology and electrical properties
}

S. Desbief, G. Derue, Ph. Leclère, S. Lenfant, D. Vuillaume, R. Lazzaroni

\section{To cite this version:}

S. Desbief, G. Derue, Ph. Leclère, S. Lenfant, D. Vuillaume, et al.. Doping of poly(3-hexylthiophene) nanofibers: microscopic morphology and electrical properties. European Physical Journal: Applied Physics, EDP Sciences, 2009, 46 (1), pp.1-5. 10.1051/epjap/2009017 . hal-00480147

\section{HAL Id: hal-00480147 \\ https://hal.archives-ouvertes.fr/hal-00480147}

Submitted on 3 May 2010

HAL is a multi-disciplinary open access archive for the deposit and dissemination of scientific research documents, whether they are published or not. The documents may come from teaching and research institutions in France or abroad, or from public or private research centers.
L'archive ouverte pluridisciplinaire HAL, est destinée au dépôt et à la diffusion de documents scientifiques de niveau recherche, publiés ou non, émanant des établissements d'enseignement et de recherche français ou étrangers, des laboratoires publics ou privés. 


\title{
Doping of poly(3-hexylthiophene) nanofibers: microscopic morphology and electrical properties
}

\author{
Simon Desbief ${ }^{1 *}$, Gwennaelle Derue ${ }^{1}$, Philippe Leclère ${ }^{1}$, Stéphane Lenfant $^{2}$, \\ Dominique Vuillaume ${ }^{2}$, Roberto Lazzaroni ${ }^{1}$ \\ ${ }^{1}$ Laboratory for Chemistry for Novel Materials, University of Mons Hainaut/Materia Nova, 20 Place du Parc, B- \\ 7000, Mons (Belgium) \\ ${ }^{2}$ Molecular Nanostructures and Devices group, Institute for Electronics, Microelectronics and Nanotechnology \\ (IEMN), CNRS, Avenue Poincaré, BP 60069, F-59652 cedex, Villeneuve d'Ascq (France)
}

PACS: 82.35.Cd; 87.64.Dz; 81.07.Nb

Running title: Doping of P3HT nanofibers

*Corresponding author: Dr. Simon Desbief; tel + 32653738 68; fax: + 32653738 61; e-mail:

sdesbief@averell.umh.ac.be

\section{Abstract}

The microstructure of thin deposits of poly(3-hexylthiophene) on silicon surfaces is investigated as a function of the solution concentration, the maturation time and the solvent nature, with the aim of generating one monolayer of $\mathrm{P} 3 \mathrm{HT}$ nanofibers on the surface. These films are then exposed to a $\mathrm{NOPF}_{6}$ solution, in order to oxidize the conjugated system and to produce conducting nanostructures. The effect of the chemical doping on the microscopic morphology and the electrical properties is analyzed on the basis of AFM and I-V measurements.

\section{Introduction}

Solution-processable semiconducting polymers are intensively studied for their potential for applications in organic electronic devices. In this context, poly(3-alkylthiophene)s, in particular poly(3-hexylthiophene) ( $\mathrm{P} 3 \mathrm{HT}$, Figure $1 \mathrm{left}$ ), are drawing strong interest due to the ease of synthesis and processability and the high charge carrier mobility [1-10].

Since the charge transport properties in conjugated polymer thin films and the device performances are intimately related to the microscopic morphology arising from the longrange order [11], it is essential to control the supramolecular organization and particularly the chain orientation in thin film deposits. Such control can be exerted through the processes used for film deposition from solution. In appropriate conditions of sample preparation, $\mathrm{P} 3 \mathrm{HT}$ chains can spontaneously self-assemble in nanofibers (Figure 1 center). It has been established that the fibers width and height correspond to the P3HT chain length 
and width, respectively [12-16]. In these structures, P3HT chains are therefore $\pi$-stacked perpendicular to the fiber axis and edge-on with respect to the substrate (Figure 1 right). Such fibrillar structure in P3HT films leads to higher charge carrier mobility than in untextured $\mathrm{P} 3 \mathrm{HT}$ films, suggesting that those nanofibers act as efficient paths for the charge carrier transport [12].

In this work we first determine the optimal preparation conditions for generating a welldefined fibrillar morphology in $\mathrm{P} 3 \mathrm{HT}$ films, with the specific goal of obtaining one dense monolayer of nanofibers on the substrate. We then investigate the effect of chemical doping of $\mathrm{P} 3 \mathrm{HT}$ on the morphology of the deposits and we characterize the electrical properties of films of doped nanofibers.

\section{EXPERIMENTAL SECTION}

\subsection{Film preparation}

Regio-regular P3HT from Aldrich is solubilized in ortho-xylene with a concentration ranging from 0.01 to $2.5 \mathrm{mg} / \mathrm{mL}$, depending on the final thickness desired. The solution is stirred and heated up to $80^{\circ} \mathrm{C}$ for 20 minutes in order to totally solubilize the polymer, and then cooled down to room temperature before deposition. 10 to $20 \mu \mathrm{L}$ of solution are drop-cast on the substrate (usually silicon (111)) under a solvent saturated atmosphere, in order to slow down the solvent evaporation. This "solvent annealing" process is expected to bring the system towards the most stable configuration.

The doping process is carried out from a liquid phase: the substrate covered with the P3HT film is immersed in the dopant solution, which is composed of an oxidizing agent dissolved in a non-solvent of the polymer [17]. In this work, we chose to work with $\mathrm{NOPF}_{6} 0.5 \mathrm{mg} / \mathrm{mL}$ in acetonitrile. The effectiveness of the doping process can be visualized by the color change of the polymer deposit (in the case of the thick films); typically the immersion time varies from a few seconds to one minute, depending on the film thickness. Finally, the sample is rinsed in pure acetonitrile in order to remove any dopant excess and dried in an air flow.

\subsection{Morphological characterization}

AFM measurements were performed using a Multimode microscope equipped with a Nanoscope $V$ controller from Veeco Instruments Inc. All images were taken under ambient conditions, in Tapping AFM mode, with Si cantilevers with a resonance frequency in the $150-300 \mathrm{kHz}$ range.

\subsection{Electrical measurements}

Current-voltage (I-V) curves were obtained in a glove-box filled with $\mathrm{N}_{2}$ (with $\mathrm{H}_{2} \mathrm{O}$ and $\mathrm{O}_{2}$ levels below $1 \mathrm{ppm})$, using a prober connected to an Agilent $4155 \mathrm{C}$ apparatus. The P3HT films were deposited on microfabricated patterns made of $8 \mathrm{~nm}$-thick platinum contacts with variable width (from 3 to 100 $\mu \mathrm{m}$ ) and gap (from 30 to $1000 \mathrm{~nm}$ ), deposited on Si with a $1 \mathrm{~nm}$ titanium layer, see Figure 2. These small values of the electrode separation ensure that the gap can be brigded by the nanofibers. The Si substrate surface is a $10 \mathrm{~nm}$-thick $\mathrm{SiO}_{2}$ layer for electrode isolation. 


\section{RESULTS AND DISCUSSION}

\subsection{Morphology}

The choice of ortho-xylene as the solvent was motivated by the fact that it favors the formation of fibrillar aggregates, compared to chloroform, tetrahydrofuran, toluene or trifluorotoluene [18]. The formation of fibrils initially takes place in solution; then they most probably adsorb and grow on the substrate as the solvent evaporates. The key issue at this stage is to optimize the polymer solution concentration and the deposition procedure to obtain a given amount of nanofibers on the substrate surface. In particular, we aim at generating a dense monolayer of fibrils, in order to study the electrical properties of such well-defined system. We thus prepared solutions with concentrations ranging from 0.01 $\mathrm{mg} / \mathrm{mL}$ to $2.5 \mathrm{mg} / \mathrm{mL}$. At the lowest concentration, only a few isolated fibrils are present on the surface (data not shown). A concentration of $0.25 \mathrm{mg} / \mathrm{mL}$ leads to the formation of a close-packed single layer of fibrils covering almost all the surface (Figure 1 center). Further increasing the concentration of the $\mathrm{P} 3 \mathrm{HT}$ solution only increases the thickness as well as the disorder within the film (with larger untextured aggregates also present). With a concentration of $2.5 \mathrm{mg} / \mathrm{mL}$, the film thickness reaches one micrometer.

The P3HT chains self-assembly in ortho-xylene can also be illustrated by Figure 3, which shows $5 \times 5 \mu^{2}$ AFM images of P3HT films deposited after different maturation times of the same solution $(0.25 \mathrm{mg} / \mathrm{mL})$. Using a freshly-made solution leads to a film composed of an uniform monolayer of close-packed fibrils with some isolated randomy-oriented fibrils above it (Figure 3A). After a maturation period of 24 and 48 hours, the amount of unorganized fibrils gradually increases (Figure $3 \mathrm{~B}$ and $\mathrm{C}$, respectively). This observation indicates that the fibrils formation begins in solution: the number of fibrils therefore increases with the maturation time [18].

\subsection{Effect of doping on the morphology}

$\mathrm{NOPF}_{6}$ dissociates in acetonitrile into $\mathrm{NO}^{+}$and $\mathrm{PF}_{6}{ }^{-}$ions. The former is an oxidizing agent that removes electrons from the $\mathrm{P} 3 \mathrm{HT}$ backbone [17]. This creates positive polarons which are compensated by $\mathrm{PF}_{6}{ }^{-}$counterions incorporating in the film (the reduced NO molecule simply leaves the system as a gas).

In order to characterize the effect of the doping process on the film morphology, we made compared AFM images before and after doping (Figure 4). Those images clearly show that the doping process does not lead to a change in morphology: the fibrillar structure is preserved while the reaction between $\mathrm{P} 3 \mathrm{HT}$ and $\mathrm{NOPF}_{6}$ occurs. This observation is very relevant since this particular morphology is very favorable for inter-chain charge transport, thanks to the $\pi$-stacking between the P3HT backbones. 
The histogram at the bottom of Figure 4 shows the distribution of the fibril width measured on the AFM images. It clearly appears that the two distributions are not centered on the same average value: for the undoped system, the average width is $20.2 \mathrm{~nm}$, which is consistent with the model of Figure 1 and the molecular weight, while for the doped fibrils, the average width is $24.1 \mathrm{~nm}$. The exact location of the $\mathrm{PF}_{6}{ }^{-}$ions with respect to the polymer chains is not known; one can nevertheless hypothesize that they incorporate next to the conjugated backbones. This may lead to a lateral shift of the polymer chains with respect to each other, which in turn would induce some disordering and an overall broadening of the nanofibers.

\subsection{Electrical characterization}

The AFM image of Figure $2 \mathrm{~B}$ clearly shows a web of nanofibers crossing the channels between the electrodes. The corresponding topographic profile indicates a variation of about 2-3 nm in the channel, consistent with the thickness of a single layer of P3HT fibrils. Figure 5 displays typical I-V curves recorded on those structures. The maximum current for the doped deposit is 100 times higher than for the undoped system (panel A), which clearly indicates that even a single monolayer of nanofibers is sufficiently continuous to become conducting upon doping. Since very few fibrils overlap or connect in those very thin deposits, these data most probably reflect the charge transport process along individual fibrils. When the P3HT deposit is thicker (for instance, $1 \mu \mathrm{m}$ ), the conductivity increases by nearly 6 orders of magnitude upon doping (Figure 5B), consistent with the expected behavior for conjugated polymers in the bulk. The much larger current recorded for the thick doped film, compared to the thin doped deposit, is certainly due to the presence of a lot more paths of conduction in the thick film, due to the presence of a thick web of nanofibers.

From the I-V curves recorded on electrode patterns with different lengths and gaps, we attempted to estimate the conductivity of the single layer deposits. For this purpose, we have considered that the conduction channel is made of a close-packed monolayer of fibrils (with a thickness of $2 \mathrm{~nm}$ ). The results are displayed in Figure $5 \mathrm{C}$, with the different curves corresponding to different electrode pattern geometries. The highest conductivities reach values of a few thousands $\mathrm{S} / \mathrm{m}$, close to the values obtained for bulk doped polythiophenes. This is a clear indication that the very thin deposits effectively conduct charges.

Finally, we have observed that the conductivity of the thick doped films significantly decreases with time when they are exposed to the ambient atmosphere. This effect, which may be due to water adsorption or to dedoping, is under investigation.

\section{CONCLUSIONS}


In this work, we have prepared thin P3HT deposits with the aim of favoring the formation of fibrillar morphologies, which are expected to be well suited for charge transport. We have determined the optimal preparation conditions to generate deposits consisting of a closepacked single layer of nanofibers. We have then carried out the chemical doping of those thin deposits from the liquid phase and we have observed that the doping process can preserve the fibrillar morphology. The width of the nanofibers slightly increases, most probably due to the incorporation of $\mathrm{PF}_{6}{ }^{-}$counterions in the vicinity of the polymer chains. The electrical characterization of the doped systems has shown that the single layer deposits can effectively conduct charges, with conductivities close to the bulk values for conducting polymers. In order to complement these first results, conducting-AFM measurements are in progress on both doped and undoped films in order to characterize the electrical properties of single nanofibers.

\section{Acknowledgements}

This work was supported by the Belgian Federal Science Policy Office (PAI 6/27) and the Belgian National Fund for Scientific Research (FRS-FNRS). G.D. is grateful to FRIA for a doctoral fellowship. Ph.L. is a Research Associate of FRS-FNRS.

\section{References}

1 C.D. Dimitrakopoulos, P.R.L. Malenfant, Adv. Mater. 14, 99 (2002)

$2 \quad$ G. Horowitz, J. Mater. Res. 19, 1946 (2004)

3 C.D. Dimitrakopoulos, D.J. Masacaro, IBM J. Res. Dev. 45, 11 (2001)

$4 \quad$ W. Fix, A. Ullmann, J. Ficker, W. Clemens, Appl. Phys. Lett. 81, 1735 (2002)

5 Z. Bao, A. Dodabalapur, A.J. Lovinger, Appl. Phys. Lett. 69, 4108 (1996)

$6 \quad$ H. Sirringhaus, N. Tessler, R.H. Friend, Science 280, 1741 (1998)

7 J. Liu, E.N. Kadnikova, Y. Liu, M.D. McGehee, J.M.J. Frechet, J. Am. Chem. Soc. 126, 9486 (2004)

8 G. Wang, J. Swensen, D. Moses, A.J. Heeger, J. Appl. Phys. 93, 6137 (2003)

9 G. Wang, D. Moses, A.J. Heeger, J. Appl. Phys. 95, 316 (2004)

10 J.F. Chang., S. Baoquan, D.W. Breiby, M.M. Nielsen, T.I. Sölling, M. Giles, I. McCulloch, H. Sirringhaus, Chem. Mater. 16, 4772 (2004)

11 H. Sirringhaus, P.J. Brown, R.H. Friend, M.M. Nielsen, K. Bechgaard, B.M.W. Langeveld-Voss, A.J.H. Spiering, R.A.J. Janssen, E.W. Meijer, P. Herwig, D.M. de Leeuw, Nature 401, 685 (1999)

12 M. Surin, Ph. Leclère, R. Lazzaroni, J.D. Yuen, G. Wang, D. Moses, A.J. Heeger, S. Cho, K. Lee, J. Appl. Phys. 100, 33712 (2006) 
13 H. Yang, S. Park, D. Kim, S. Magonov, K. Cho, T. Chang, Z. Bao, C.R. Ryu, Polym. Preprints 44, $333(2003)$

14 R.J. Kline, M.D. McGehee, Adv. Mater. 15, 1519 (2003)

15 J.A. Merlo, C.D. Frisbie, J. Phys. Chem. B 108, 19169 (2004)

16 R. Zhang, B. Li, M.C. Iovu, E.LM. Jeffries, G. Sauve, J. Cooper, S. Jia, S. Tristram-Nagle, D.M. Smilgies, D.N. Lambeth, R.D. McCullough, J. Kowalewski, J. Am. Chem. Soc. 128, 3450 (2006)

17 R. Lazzaroni, M. Lögdlund, S. Stafström, W.R. Salaneck, J.L. Brédas, J. Chem. Phys. 93, 4433 (1990)

18 S. Berson, PhD.Thesis, University Joseph-Fourier Grenoble, 2007 


\section{Figure captions}

Figure 1: Molecular structure of P3HT (left); $1 \times 1 \mu \mathrm{m}^{2}$ AFM image of a thin deposit of P3HT showing a fibrillar morphology (center); model of the chain packing in the nanofibers (right).

Figure 2 : 10x10 $\mu \mathrm{m}^{2}$ AFM images of a pattern for electrical measurements (width:10 $\mu \mathrm{m}$; gap:100 $\mathrm{nm}$ ) before (left) and after (right) P3HT deposition.

Figure $3: 5 \times 5 \mu \mathrm{m}^{2}$ AFM images of films deposited after:

A: a few minutes, B: 24 hours and C: 48 hours of maturation time.

All films were deposited from the same solution of P3HT $0.25 \mathrm{mg} / \mathrm{mL}$ in ortho-xylene. The vertical color scale is $8(A)$ and $16(B, C) n m$, respectively.

Figure $4: 2 \times 2 \mu \mathrm{m}^{2}$ AFM images of P3HT films:

A: undoped , B: doped with a $0.5 \mathrm{mg} / \mathrm{mL} \mathrm{NOPF}_{6}$ solution in acetonitrile.

C: Distribution of the nanofiber width for the undoped and doped systems.

Figure 5 : I(V) curves measured for P3HT films deposited on $10 \mu \mathrm{m}$-long electrodes with a $50 \mathrm{~nm}$ gap. A: for a single layer of nanofibers; B: for a $1 \mu \mathrm{m}$-thick deposit

C: Conductivity estimates for the single layer deposits; the different curves correspond to different electrode pattern geometries. 

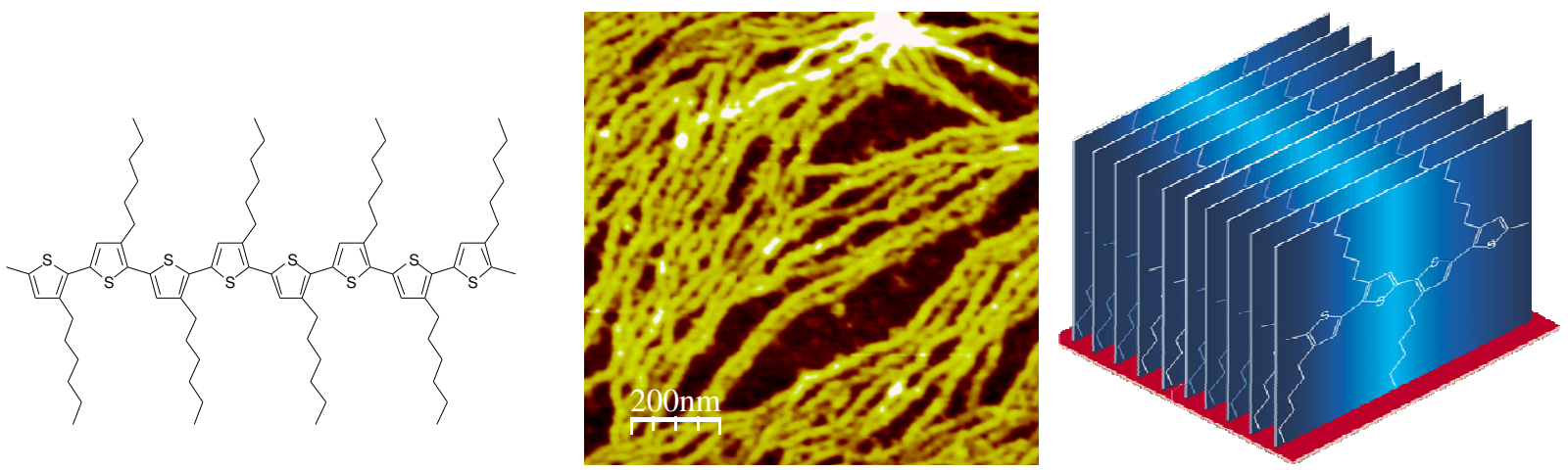

Figure 1: Molecular structure of P3HT (left); $1 \times 1 \mu \mathrm{m}^{2}$ AFM image of a thin deposit of P3HT showing a fibrillar morphology (center); model of the chain packing in the nanofibers (right). 

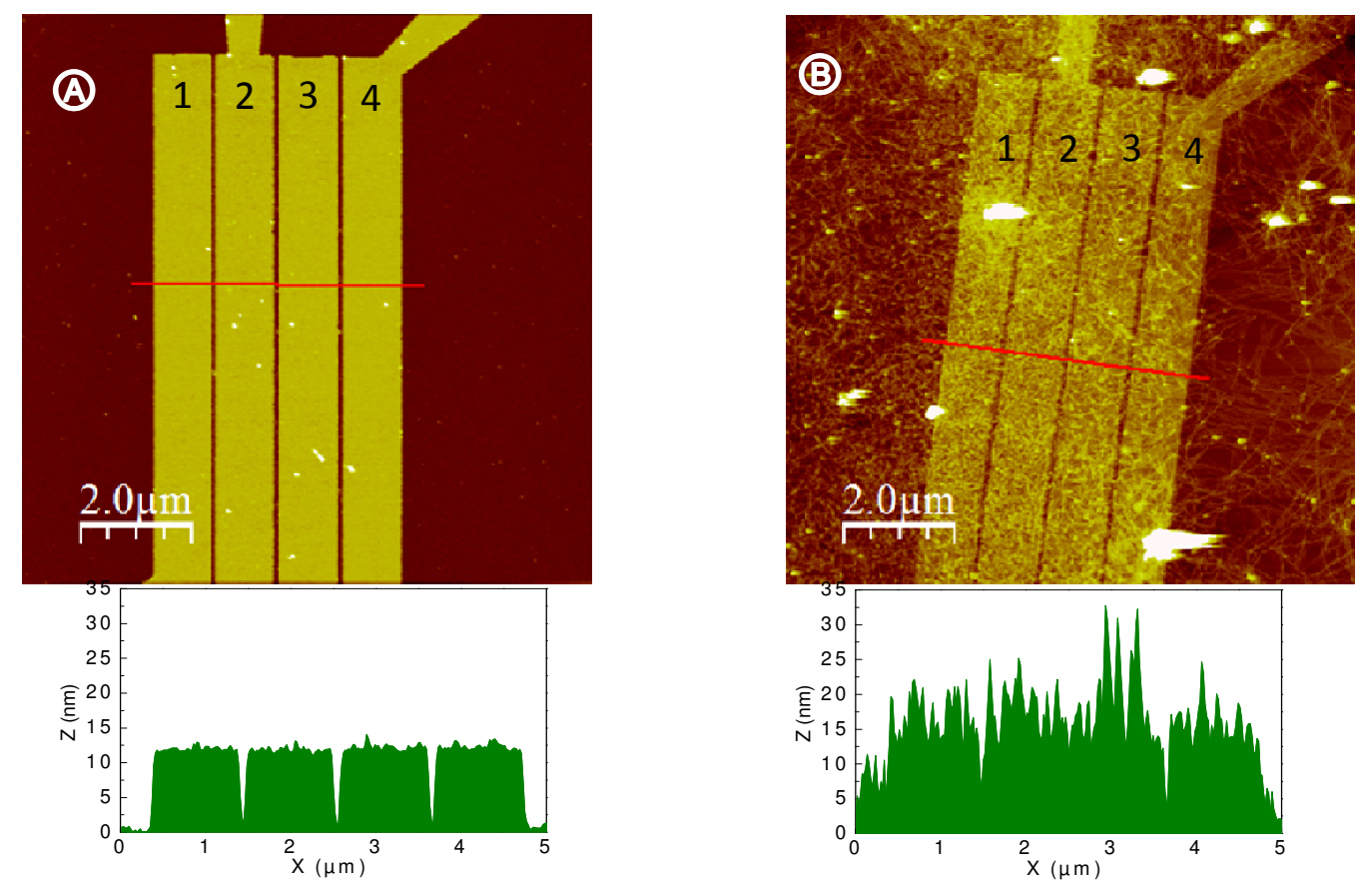

Figure 2 : 10x10 $\mu \mathrm{m}^{2}$ AFM images of a pattern for electrical measurements (width:10 $\mu \mathrm{m}$; gap:100 $\mathrm{nm}$ ) before (left) and after (right) P3HT deposition. 

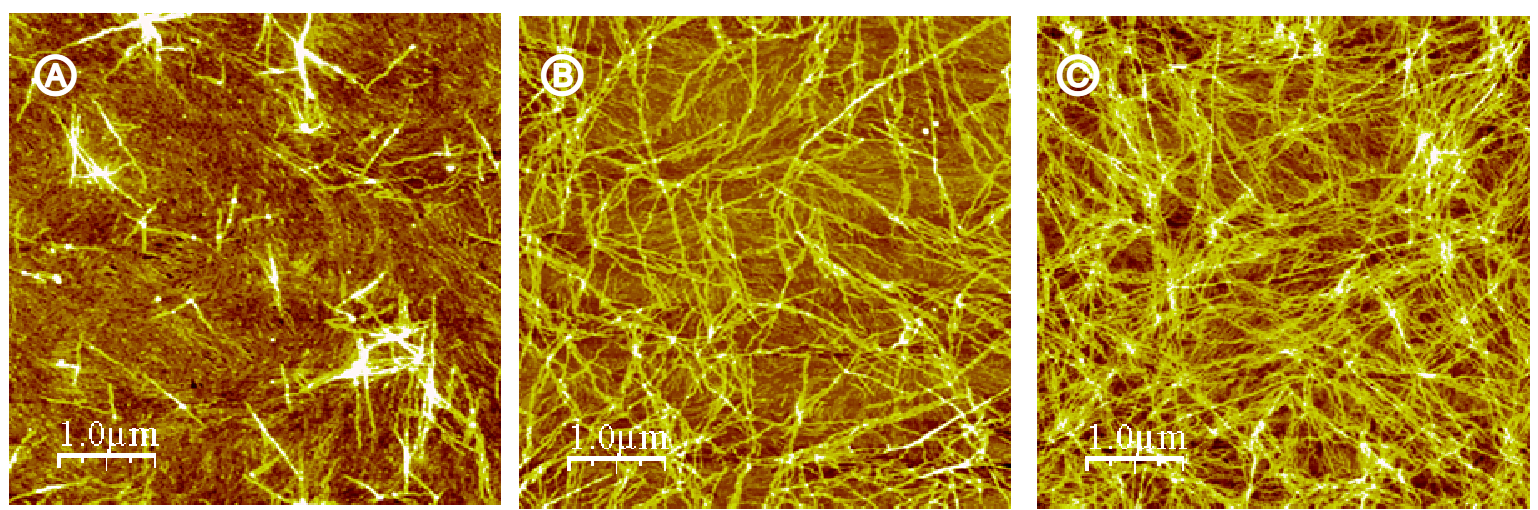

Figure $3: 5 \times 5 \mu \mathrm{m}^{2}$ AFM images of films deposited after

A: a few minutes, B: 24 hours and C: 48 hours of maturation time.

All films were deposited from the same solution of $\mathrm{P} 3 \mathrm{HT} 0.25 \mathrm{mg} / \mathrm{mL}$ in ortho-xylene. The vertical color scale is $8(A)$ and $16(B, C) n m$, respectively. 

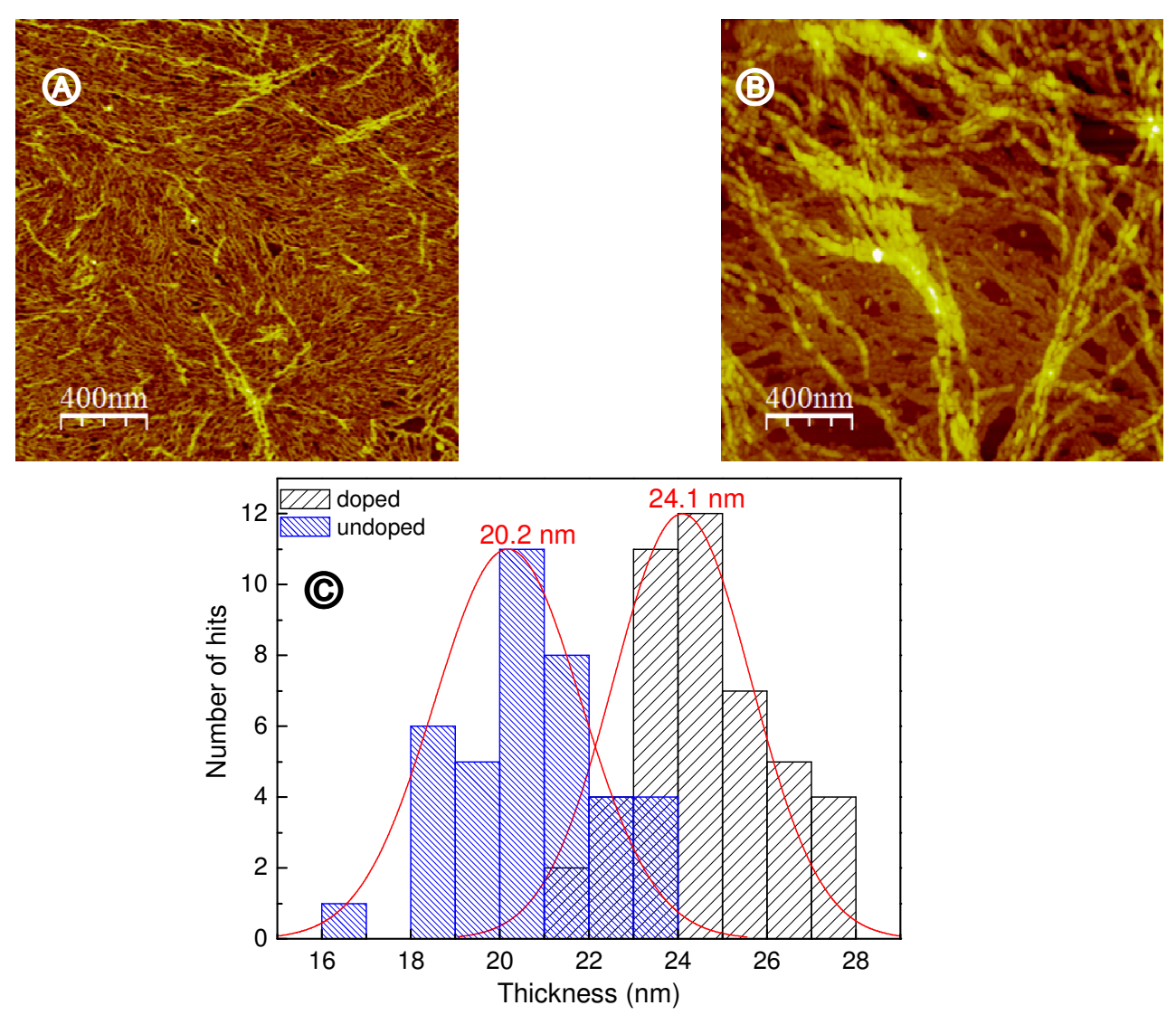

Figure $4: 2 \times 2 \mu \mathrm{m}^{2}$ AFM images of P3HT films

A: undoped , B: doped with a $0.5 \mathrm{mg} / \mathrm{mL}$ NOPF $_{6}$ solution in acetonitrile.

C: Distribution of the nanofiber width for the undoped and doped systems. 

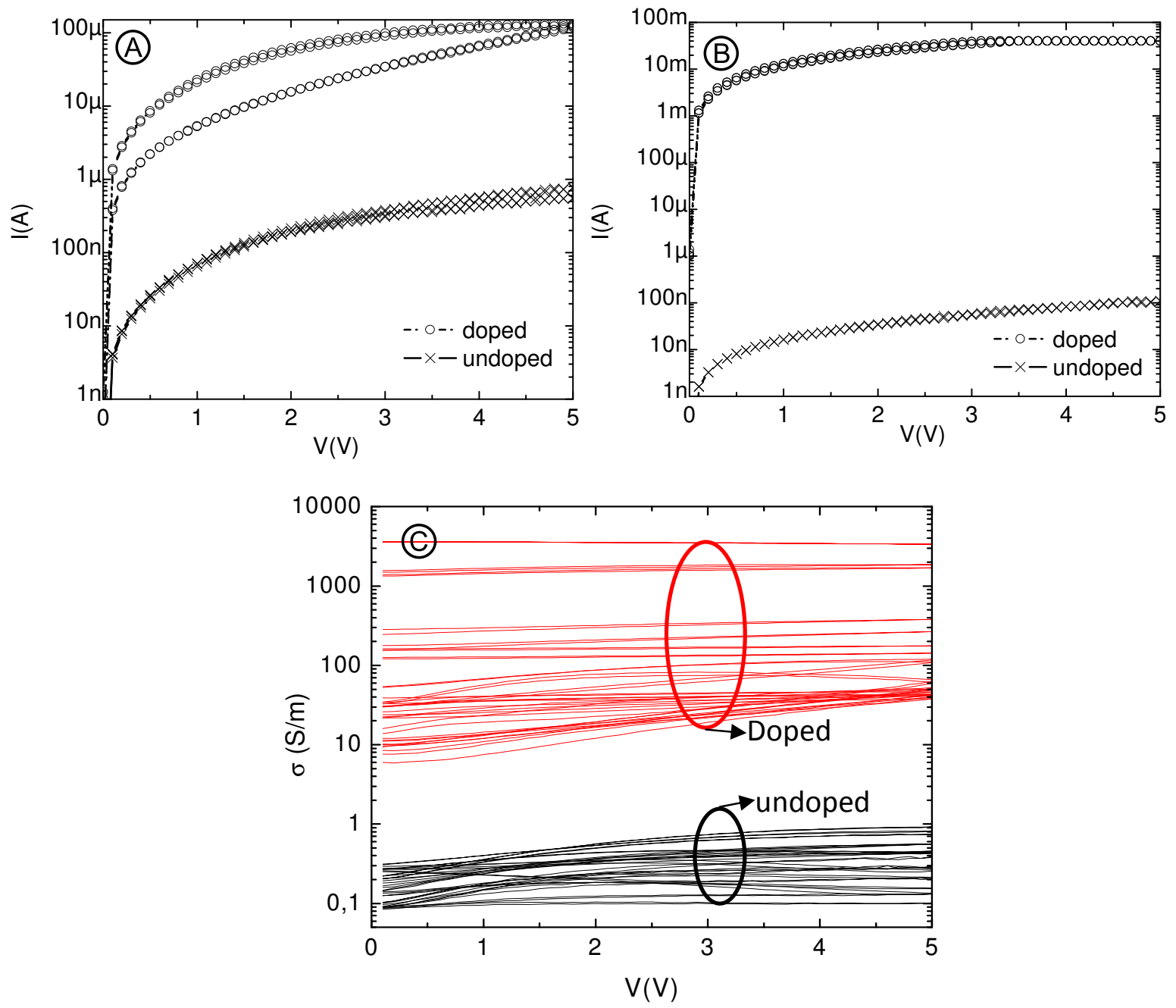

Figure 5 : I(V) curves measured for P3HT films deposited on $10 \mu \mathrm{m}$-long electrodes with a $50 \mathrm{~nm}$ gap. A: for a single layer of nanofibers $\quad B$ : for a $1 \mu \mathrm{m}$-thick deposit

C: Conductivity estimates for the single layer deposits; the different curves correspond to different electrode pattern geometries. 